\title{
COMPARATIVE STUDY OF TRANSVAGINAL SONOGRAPHY AND HYSTEROSCOPY FOR THE DETECTION OF PATHOLOGICAL ENDOMETRIAL LESIONS IN WOMEN WITH PERIMENOPAUSAL BLEEDING
}

By

\section{Amr Abd-Allah Roshdy Hassan, Esmail Mohamed El-Garhy and Ashraf Hamdy Mohamed}

Department of Obstetrics and Gynecology Department, Faculty of Medicine, Al-Azhar University

Corresponding author: Amr Abd-Allah Roshdy Hassan, E-mail: amrroshdy321@gmail.com

\begin{abstract}
Background: Abnormal uterine bleeding is a common gynecological presentation in outpatient clinic, but is often complex and difficult to diagnose. Abnormal uterine bleeding (AUB) is the main reason in women to refer to gynecologists and accounts for two thirds of all hysterectomies.

Objectives: The aim of this study was to compare the diagnostic accuracy of two dimensional transvaginal ultrasound and hysteroscopy referring to histopathology in evaluation of uterine cavity lesions in perimenopausal women with abnormal uterine bleeding.

Subjects and methods: This was a prospective cohort study. The study was carriedout at Al Agouza Police Hospital, on fifty women in peri-menopausal period, The study was conducted the period from April 2019 till December 2019. All participants received comprehensive information regarding objective and the expected benefit of the study. All ethical considerations were taken throughout the whole work.

Results: The results of the study revealed that sensitivity 2D TVS in detection of endometrial hyperplasia was $100 \%$, specificity was $88.7 \%$, PPV was $73.30 \%$, NPV was $100 \%$, and accuracy was $94 \%$ with area under ROC curve 0.99 , and sensitivity of hystroscope in detection of endometrial polyp was $36.3 \%$, specificity was $100 \%$, PPV was $100 \%$, NPV was $84.7 \%$, accuracy was $86 \%$ with area under ROC curve 0.45 .

Conclusion: Transvaginal sonography has a moderate diagnostic accuracy in detecting endometrial hyperplasia and other intrauterine pathology. It is safe, acceptable and easily available in most secondary and tertiary care setting and is noninvasive. It should be continued as 1st line diagnostic tool in patients with abnormal uterine bleeding in perimenopausal women.
\end{abstract}

Keywords: Perimenopausal, Transvaginal Sonography, Abnormal Uterine Bleeding, Diagnostic, endometrial, Intrauterine, Hysteroscopy.

\section{INTRODUCTION}

Abnormal uterine bleeding (AUB) is the main reason women are referred to gynecologists and accounts for two thirds of all hysterectomies (Sun et al., 2018).
AUB is responsible for as many as one-third of all outpatient gynecologic visits and this proportion rises to $69 \%$ in a perimenopausal (Whitaker and Critchley, 2016). 
In perimenopausal women, AUB is diagnosed when there is a substantial change in frequency, duration, or amount of bleeding during or between periods. In postmenopausal women (mostly between 45-55 years old), any vaginal bleeding 1 year after cessation of menses is considered abnormal (Verma et al., 2014).

The cause of AUB in perimenopausal women is found in $50 \%$ to $60 \%$ of cases. The remaining cases, where no organic cause is found, are classified as dysfunctional uterine bleeding "DUB" (Albers et al., 2010).

Diagnostic procedures for anatomic changes and for endometrial carcinoma include ultrasonography, diagnostic hysteroscopy, sonohysterogram, and dilation and curettage (D\&C) (Shokouhi, 2015).

Ultrasonography used to look for ovarian or uterine disease and endometrial biopsy (EMB). Transvaginal Sonography (TVS) is $80 \%$ sensitive and $69 \%$ specific for fibroids and polyps and is superior to transabdominal ultrasound (TAS). If possible, TVS should be performed on days 4 to 6 of the menstrual cycle .In perimenopausal women, there is no known correlation between endometrial thickness seen on ultrasound scan and endometrial disease (Veena \& Shivalingaiah, 2014 and Shobhitha et al., 2015).

Hysteroscopy allows direct visualization of the endometrial cavity and is usually combined with EMB (Ratner et al., 2019).

Evaluation of AUB in perimenopausal women is challenging. As a result of the decline in ovarian function, changes in menstrual cycles are common in these women. As with postmenopausal bleeding, abnormal perimenopausal bleeding is associated with endometrial carcinoma in approximately $10 \%$ of cases so evaluation of women's risk factors for endometrial hyperplasia or carcinoma is recommended (Dueholm and Hjorth, 2017).

The aim of this study was to compare the diagnostic accuracy of two dimensional transvaginal ultrasound and hysteroscopy referring to histopathology in evaluation of uterine cavity lesions in perimenopausal women with abnormal uterine bleeding.

\section{PATIENTS AND METHODS}

This was a prospective cohort study, which was carried out Al-Agouza Police Hospital, carried on fifty women in perimenopausal period. The study was conducted during the period from April 2019 till December 2019.

The researcher introduced himself to all participants included in this study and asked them to participate after illustrating the goal of the study. All participants received comprehensive information regarding objective and the expected benefit of the study. All ethical considerations were taken throughout the whole work.

\section{Inclusion criteria:}

Perimenopausal age group (40-55 years) having abnormal uterine bleeding.

\section{Exclusion criteria:}

- History of drug intake that can lead to vaginal bleeding. 
- Evidence of general cause that can cause vaginal bleeding, e.g: Blood clotting disorder, thyroid disease, chronic liver failure.

- Vaginal, vulval or cervical causes of bleeding.

- Using any local or hormonal method of contraception e.g: trauma, tampon use, intrauterine device, forigen body.

\section{All patients wer subjected to:}

- History, clinical examination and laboratory investigations including $\mathrm{CBC}$, coagulation profile, fasting and post prandial blood sugar, liver and kidney function and pregnancy test, conventional 2D- Transvaginal ultrasonography using general electric (GE) logic 200 ultrasound machine with a transvaginal probe (GE 6.5
MTZ) measuring uterine size and endometrial thickness, looking for endometrial polypi and any relevant adnexal pathology and hysteroscopic examination using Karl Storz "office hysteroscope" (Germany), fractional curettage.

- All the specimens were placed in formalin $10 \%$ and sent for histopathological correlation.

\section{Statistical analysis:}

Analysis of data was done using Statistical Pakage for the Social Science version 20 (SPSS Inc., Chicago, IL, USA). Quantitative variables were described in the form of mean and standard deviation. Qualitative variables were described as number and percent. $\mathrm{P}$ value $<0.05$ is considered significant.

\section{RESULTS}

Fifty 50 perimenopausal women with AUB who were included had age ranged from 40-54years (mean of $46.5 \pm 4.1 \mathrm{ys}$ ) and their parity ranged from 0-7 (mean $3.6 \pm 1)$.the majority of our sample were multiparous (90\%) (Table 1).

Table (1): Age and parity of the patient

\begin{tabular}{|c|c|c|}
\hline AGE & \multicolumn{2}{|c|}{$46.5 \pm 4.1$} \\
Mean age $( \pm$ SD $)$ & \multicolumn{2}{|c|}{$40-54$} \\
Range & \multicolumn{2}{|c|}{} \\
\hline Parity & \multicolumn{2}{|c|}{$3.6 \pm 1$} \\
Mean parity $( \pm$ SD $)$ & No. & $\%$ \\
Range & 5 & $10.0 \%$ \\
\hline Nulliparous & 45 & $90.0 \%$ \\
\hline Multiparous &
\end{tabular}

Endometrial hyperplasia was the most frequent finding by TVS $(30 \%)$ with a mean endometrial thickness of $11.3 \pm 2.1$ mm followed by endometrial polyp (28\%) with a mean endometrial thickness of 21.3 $\pm 2.3 \mathrm{~mm}$ (Table 2). 
Table (2): Transvaginal sonography findings:

\begin{tabular}{|c|c|c|}
\hline TVS Diagnosis & Total & Mean \pm SD \\
\hline Normal endometrium & $10(20 \%)$ & $6.6 \pm 1.0$ \\
\hline Endometrial thickness 8 mm & $15(30 \%)$ & $11.3 \pm 2.1$ \\
\hline Endometrial thickness 8 mm + Adenomyosis & $3(6 \%)$ & $10.2 \pm 2.8$ \\
\hline Adenomyosis & $4(8 \%)$ & $6.1 \pm 0.7$ \\
\hline Endometrial Polyp & $14(28 \%)$ & $21.3 \pm 2.3$ \\
\hline Submucosal fibroid & $4(8 \%)$ & $8.7 \pm 2.9$ \\
\hline TOTAL & $50(100 \%)$ & - \\
\hline
\end{tabular}

The commonest lesion diagnosed by histopathology is endometrial hyperplasia which was found in $50 \%$ of the examined specimen and $38 \%$ of ultrasonic findings. Using hysteroscopy the commonest lesion diagnosed was endometrial polyp which was found in $28 \%$ of cases while endometrial hyperplasia found only in 20\% (Table 3).

Table (3): Hysteroscopy findings

\begin{tabular}{|c|c|c|}
\hline Findings & Number & Percent \\
\hline Normal Endometrium & 19 & $38 \%$ \\
\hline Endometrial Hyperplasia & 10 & $20 \%$ \\
\hline Endometrial Polyp & 14 & $28 \%$ \\
\hline Adenomyosis & 4 & $8 \%$ \\
\hline Submucosal Fibroid & 3 & $6 \%$ \\
\hline TOTAL & 50 & $100 \%$ \\
\hline
\end{tabular}

Sensitivity 2 D TVS in detection of endometrial hyperplasia was $100 \%$, specificity was $89.7 \%$, PPV was $73.30 \%$, NPV was $100 \%$, accuracy was $94 \%$ with area under ROC curve 0.99 . Sensitivity 2 D TVS in detection of endometrial polyp was $93.3 \%$, specificity was $100 \%$, PPV was $100 \%$, NPV was $97.2 \%$, accuracy was $100 \%$ with area under ROC curve
1.0. Sensitivity 2 D TVS in detection of endometrial polyp was $63.6 \%$, specificity was $100 \%$, PPV was $100 \%$, NPV was $90.7 \%$, accuracy was $92 \%$ with area under ROC curve 0.71 . Sensitivity 2 D TVS in detection of submucus fibroid was $100 \%$, specificity was $95.8 \%$, PPV was $50 \%$, NPV was $100 \%$, accuracy was $92 \%$ with area under ROC curve 0.71 (Table 4). 
Table (4): Validity of of 2 D TVS in detection of endometrial hyperplasia, endometrial polyp, adenomyosis and submucus fibroid

\begin{tabular}{|c|c|c|c|}
\hline \multicolumn{2}{|c|}{$\begin{array}{ll}2 \text { D TVS } & \text { Histopatology } \\
\end{array}$} & Positive & Negative \\
\hline \multirow{7}{*}{$\begin{array}{l}\text { Endometrial } \\
\text { hyperplasia }\end{array}$} & $\begin{array}{l}\text { Positive } \\
\text { Negative }\end{array}$ & $\begin{array}{c}11 \\
0\end{array}$ & $\begin{array}{c}4 \\
35\end{array}$ \\
\hline & AUC & \multicolumn{2}{|c|}{0.99} \\
\hline & Sensitivity & \multicolumn{2}{|c|}{100.0} \\
\hline & Specificity & \multicolumn{2}{|c|}{89.7} \\
\hline & PPV & \multicolumn{2}{|c|}{73.3} \\
\hline & NPV & \multicolumn{2}{|c|}{100.0} \\
\hline & Accuracy & \multicolumn{2}{|c|}{94.0} \\
\hline \multirow{7}{*}{$\begin{array}{c}\text { Endometrial } \\
\text { polyp }\end{array}$} & $\begin{array}{l}\text { Positive } \\
\text { Negative }\end{array}$ & $\begin{array}{c}14 \\
1\end{array}$ & $\begin{array}{c}0 \\
35\end{array}$ \\
\hline & AUC & \multicolumn{2}{|c|}{1.0} \\
\hline & Sensitivity & \multicolumn{2}{|c|}{93.3} \\
\hline & Specificity & \multicolumn{2}{|c|}{100.0} \\
\hline & PPV & \multicolumn{2}{|c|}{100.0} \\
\hline & NPV & \multicolumn{2}{|c|}{97.2} \\
\hline & Accuracy & \multicolumn{2}{|c|}{100.0} \\
\hline \multirow{7}{*}{ Adenomyosis } & $\begin{array}{l}\text { Positive } \\
\text { Negative }\end{array}$ & $\begin{array}{l}7 \\
4\end{array}$ & $\begin{array}{c}0 \\
39\end{array}$ \\
\hline & AUC & \multicolumn{2}{|c|}{0.71} \\
\hline & Sensitivity & \multicolumn{2}{|c|}{63.6} \\
\hline & Specificity & \multicolumn{2}{|c|}{100.0} \\
\hline & PPV & \multicolumn{2}{|c|}{100.0} \\
\hline & NPV & \multicolumn{2}{|c|}{90.7} \\
\hline & Accuracy & \multicolumn{2}{|c|}{92.0} \\
\hline \multirow{7}{*}{$\begin{array}{l}\text { Submucus } \\
\text { Fibroid }\end{array}$} & $\begin{array}{l}\text { Positive } \\
\text { Negative }\end{array}$ & $\begin{array}{l}2 \\
0\end{array}$ & $\begin{array}{c}2 \\
46\end{array}$ \\
\hline & AUC & \multicolumn{2}{|c|}{0.71} \\
\hline & Sensitivity & \multicolumn{2}{|c|}{100} \\
\hline & Specificity & \multicolumn{2}{|c|}{95.8} \\
\hline & PPV & \multicolumn{2}{|c|}{50} \\
\hline & NPV & \multicolumn{2}{|c|}{100} \\
\hline & Accuracy & \multicolumn{2}{|c|}{92.0} \\
\hline
\end{tabular}

Sensitivity of hystroscope in detection of endometrial hyperplasia was $90.9 \%$, specificity was $100 \%$, PPV was $100 \%$, NPV was $97.5 \%$ and accuracy was $98 \%$. Sensitivity of hystroscope in detection of endometrial polyp was $93.3 \%$, specificity was $100 \%$, PPV was $100 \%$, NPV was $97.2 \%$, accuracy was $100 \%$ with area under ROC curve 1.0. Sensitivity of hystroscope in detection of endometrial polyp was $36.3 \%$, specificity was $100 \%$, PPV was $100 \%$, NPV was $84.7 \%$, accuracy was $86 \%$ with area under ROC curve 0.45 . Sensitivity of hystroscope in detection of submucus fibroid was $36.3 \%$, specificity was $100 \%$, PPV was $100 \%$, NPV was $84.7 \%$, accuracy was $86 \%$ with area under ROC curve 0.45 (Table 5). 
Table (5): Validity of hystroscope in detection of endometrial hyperplasia, endometrial polyp, adenomyosis and submucus fibroid

\begin{tabular}{|c|c|c|c|}
\hline \multicolumn{2}{|c|}{$\begin{array}{ll}\text { Hystroscope } & \text { Histopatology } \\
\end{array}$} & Positive & Negative \\
\hline \multirow{6}{*}{$\begin{array}{c}\text { Endometrial } \\
\text { hyperplasia }\end{array}$} & $\begin{array}{l}\text { Positive } \\
\text { Negative }\end{array}$ & $\begin{array}{c}10 \\
1\end{array}$ & $\begin{array}{c}0 \\
39\end{array}$ \\
\hline & Sensitivity & \multicolumn{2}{|c|}{90.9} \\
\hline & Specificity & \multicolumn{2}{|c|}{100.0} \\
\hline & PPV & \multicolumn{2}{|c|}{100.0} \\
\hline & NPV & \multicolumn{2}{|c|}{97.5} \\
\hline & Accuracy & \multicolumn{2}{|c|}{98.0} \\
\hline \multirow{7}{*}{$\begin{array}{c}\text { Endometrial } \\
\text { polyp }\end{array}$} & $\begin{array}{l}\text { Positive } \\
\text { Negative }\end{array}$ & $\begin{array}{c}14 \\
1\end{array}$ & $\begin{array}{c}0 \\
35\end{array}$ \\
\hline & AUC & \multicolumn{2}{|c|}{1.0} \\
\hline & Sensitivity & \multicolumn{2}{|c|}{93.3} \\
\hline & Specificity & \multicolumn{2}{|c|}{100.0} \\
\hline & PPV & \multicolumn{2}{|c|}{100.0} \\
\hline & NPV & \multicolumn{2}{|c|}{97.2} \\
\hline & Accuracy & \multicolumn{2}{|c|}{100.0} \\
\hline \multirow{7}{*}{ Adenomyosis } & $\begin{array}{l}\text { Positive } \\
\text { Negative }\end{array}$ & $\begin{array}{l}4 \\
7\end{array}$ & $\begin{array}{c}0 \\
39\end{array}$ \\
\hline & AUC & \multicolumn{2}{|c|}{0.45} \\
\hline & Sensitivity & \multicolumn{2}{|c|}{36.3} \\
\hline & Specificity & \multicolumn{2}{|c|}{100.0} \\
\hline & PPV & \multicolumn{2}{|c|}{100.0} \\
\hline & NPV & \multicolumn{2}{|c|}{84.7} \\
\hline & Accuracy & \multicolumn{2}{|c|}{86.0} \\
\hline \multirow{8}{*}{$\begin{array}{l}\text { Submucus } \\
\text { Fibroid }\end{array}$} & Positive & 4 & 0 \\
\hline & Negative & 7 & 39 \\
\hline & AUC & \multicolumn{2}{|c|}{0.45} \\
\hline & Sensitivity & \multicolumn{2}{|c|}{36.3} \\
\hline & Specificity & \multicolumn{2}{|c|}{100.0} \\
\hline & PPV & \multicolumn{2}{|c|}{100.0} \\
\hline & NPV & \multicolumn{2}{|c|}{84.7} \\
\hline & Accuracy & \multicolumn{2}{|c|}{86.0} \\
\hline
\end{tabular}

\section{DISCUSSION}

Fifty perimenopausal women with AUB who were included had age ranged from 40-54years (mean of 46.5 \pm 4.1ys), and their parity ranged from 0-7 (mean $3.6 \pm 1)$. The majority of our sample was multiparous $90 \%$. All the patients complained of AUB (100\%). AUB was associated with pain in $40 \%$ of the cases, and with infertility in $12 \%$ of the cases.
The commonest bleeding pattern was menorrhagia (42\%).

Normal histopathological findings were present in $20 \%$ of cases, single lesion in $48 \%$ and more than one lesion in $32 \%$ of cases. Sensitivity 2 D TVS in detection of endometrial hyperplasia was $100 \%$, specificity was $88.7 \%$, PPV was $73.30 \%$, NPV was $100 \%$, and accuracy was $94 \%$ with area under ROC curve 0.99. Sensitivity of hystroscope in 
detection of endometrial hyperplasia was $90.9 \%$, specificity was $100 \%$, PPV was $100 \%$, NPV was $97.5 \%$ and accuracy was $98 \%$.

Sensitivity 2D TVS in detection of endometrial polyp was $100 \%$, specificity was $100 \%$, PPV was $100 \%$, NPV was $100 \%$, accuracy was $100 \%$.Sensitivity of hystroscope in detection of endometrial polyp was $100 \%$, specificity was $100 \%$, PPV was $100 \%$, NPV was $100 \%$, accuracy was $100 \%$.

El-Khayat et al. (2017) conducted a study over patients with perimenopausal bleeding whose range of age 40-55 years (mean of $46.8 \pm 4.5$ years) and their parity ranged from $0-8$ (mean $3.5 \pm 2$ ).

In the present study, all the patients complained of AUB (100\%). AUB was associated with pain in $40 \%$ of the cases and with infertility in $12 \%$ of the cases. The commonest bleeding pattern was menorrhagia (42\%), followed by menometrorrhagia in $32 \%$.

El-Khayat et al. (2017) in their study demonstrated that AUB was associated with pain in $38 \%$ of the cases, and with infertility in $10 \%$ of the cases. The commonest bleeding pattern was menorrhagia $(40 \%)$ followed by menometrorrhagia in 34\%. Choudhary et al. (2017) noticed that the most common bleeding pattern was heavy menstrual bleeding (50\%). Pillai (2014) had 46.5\% patients with menstrual complaints of menorrhagia. Verma et al. (2014), in their study, had polymenorrhoea in $23 \%$ of cases and metrorrhagia in $19 \%$ of cases.

In our study, histopathology findings revealed normal histopathological findings in $20 \%$ of cases, single lesion in
$48 \%$ and more than one lesion in $32 \%$ of cases. El-Khayat et al. (2017) verified that endometrial hyperplasia was found in about half of these lesions and was associated with endometrial polyp in half of the multiple lesions.

In this study, by 2D TVS, endometrial hyperplasia was the most frequent finding by TVS $(30 \%)$ with a mean endometrial thickness of $11.3 \pm 2.1 \mathrm{~mm}$, followed by endometrial polyp (28\%) with a mean endometrial thickness of $21.3 \pm 2.3 \mathrm{~mm}$. This was in concordant with El-Khayat et al. (2017) who illustrated that endometrial hyperplasia. The most frequent finding by TVS was $32 \%$, with the appearance of well defined, thick and highly reflective layer occupying the whole of the endometrial cavity with a mean endometrial thickness of $11.2 \pm 2.4 \mathrm{~mm}$, followed by endometrial polyp (26\%) with a mean endometrial thickness of 18.0 $\pm 5.3 \mathrm{~mm}$.

On the contradict Choudhary et al. (2017) found that TVS at endometrial thickness 5 to $8 \mathrm{~mm}$, and no endometrial pathology was found. Shobhitha et al. (2015) also observed that no endometrium abnormality was found on ET $<8 \mathrm{~mm}$. Veena and Shivalingaiah (2014) revealed normal endometrium in $45 \%$ (majority of these patients had endometrial thickness less than $9 \mathrm{~mm}$ ).

In the present study by hysteroscopy, commonest findings were endometrial hyperplasia which was found in $50 \%$ of the examined specimen, and 38\% of ultrasonic findings. Using hysteroscopy, the commonest lesion diagnosed was endometrial polyp which was found in $28 \%$ of cases, while endometrial hyperplasia found only in $20 \%$. 
El-Khayat et al. (2017) found that, by hysteroscopy, the commonest lesion diagnosed was endometrial polyp which was found in $28 \%$ of cases, while endometrial hyperplasia found only in $20 \%$ with the appearance of thick endometrium with bridging between layers of the endometrium, increased vascularization, increased bleeding and polypoid formation. These changes can be focal or global.

In our study, when we compared 2D TVS ultrasound and hysteroscopy findings with histopathologic findings of tissue obtained by hysterectomy or D\&C, we found that for diagnosing endometrial hyperplasia sensitivity 2D TVS in detection of endometrial hyperplasia was $100 \%$, specificity was $88.7 \%$, PPV was $73.30 \%$, NPV was $100 \%$, accuracy was 94\% with area under ROC curve 0.99, sensitivity of hystroscope in detection of endometrial hyperplasia was $90.9 \%$, specificity was $100 \%$, PPV was $100 \%$, NPV was $97.5 \%$ and accuracy was $98 \%$.

El-Khayat et al. (2017) illustrated that 2D ultrasound show good sensitivity in detection of endometrial polyp, highest specificity and accuracy was for adenomyosis. Hysteroscopy was poorly sensitive, but highly specific for both endometrial hyperplasias.

On the other hand, Choudhary et al. (2017) reported that the sensitivity, specificity, PPV, NPV for diagnosis of endometrial hyperplasia on TVS was 81.81, 94.43\%, 90\%, 95\%, also hysteroscopy showed endometrial hyperplasia in $20 \%$ cases of AUB and other intrauterine pathology observed was polyp which was found in $16 \%$ of cases, sub mucosal fibroid in $8 \%$ of cases respectively. Shokouhi (2015) revealed that the accuracy, sensitivity, specificity, PPV, and NPV were $88.25 \%, 90.7 \%$, $84 \%, 97.7 \%$, and $84 \%$ respectively in premenopausal women in AUB patients especially in endometrial hyperplasia in their study. Also, Patil et al. (2011) showed hyperplasia in $18 \%$, endometrial polyp in $9 \%$, and sub mucosal myoma in $11 \%$.

For diagnosing endometrial polyp we founded that sensitivity 2D TVS in detection of endometrial polyp was $100 \%$, specificity was $100 \%$, PPV was $100 \%$, NPV was $100 \%$, accuracy was $100 \%$ with area under ROC curve 1.0, that sensitivity of hystroscope in detection of endometrial polyp was $100 \%$, specificity was $100 \%$, PPV was $100 \%$, NPV was $100 \%$, accuracy was $100 \%$ with area under ROC curve 1.0.

El-Khayat et al. (2017) reported that for endometrial polyp hysteroscopy was highly sensitive, specific and accurate. Ultrasound was a little more accurate than hysteroscopy in diagnosing endometrial hyperplasia, detection of endometrial polyp all accuracy measures of hysteroscopy were higher than those of ultrasound. Choudhary et al. (2017) revealed that the sensitivity, specificity, PPV, NPV was $100 \%$ for polyp and sub mucosal fibroid in hysteroscopy.

For diagnosing adenomyosis, sensitivity 2D TVS in detection of endometrial polyp was $63.6 \%$, specificity was $100 \%$, PPV was $100 \%$, NPV was $90.7 \%$, accuracy was $92 \%$ with area under ROC curve 0.71. That sensitivity of hystroscope in detection of endometrial polyp was $36.3 \%$, specificity was $100 \%$, PPV was $100 \%$, NPV was $84.7 \%$, and 
accuracy was $86 \%$ with area under ROC curve 0.45 .

El-Khayat et al. (2017) revealed that ultrasound was more accurate than hysteroscopy in diagnosing adenomyosis. Clark et al. (2018) in their meta-analysis to determine the accuracy of hysteroscopy in diagnosing endometrial cancer and hyperplasia in women with AUB, 65 primary studies were analyzed, including 26346 women, they found that the weighted overall sensitivity was $78.0 \%$ (95\% CI, 76.3\%-79.6\%) and specificity was $95.8 \%$ (95\% CI, 95.6\%-96.1\%) for endometrial hyperplasia.

To evaluate the accuracy of TVS in the diagnosis of adenomyosis, Bazot et al. (2010) found that the sensitivity, specificity, and positive and negative predictive values of TVS, $100 \%$ and $83.3 \%$, and $40 \%$ and $82.9 \%$, respectively, and the accuracy of TVS was $91.3 \%$. Our data were consistent with these findings.

The study of Özdemir et al. (2010) was undertaken to investigate cut-off value of the endometrial thickness by TVS. An optimal sensitivity and specificity (83.6 and $56.4 \%$, respectively) and NPV with $95.6 \%$ for detection of abnormal endometrium were obtained with an endometrial thickness of $8 \mathrm{~mm}$. They concluded that an endometrial thickness $>8 \mathrm{~mm}$ is more likely than that of $8 \mathrm{~mm}$ or less to be indicated with EMB in perimenopausal uterine bleeding.

Results of TVS and hysteroscopy by Ryu et al. (2010) were correlated with the pathological findings. The sensitivity and specificity were $79.0 \%$ and $45.8 \%$ for TVS, and $95.1 \%$ and $83.3 \%$ for hysteroscopy, respectively. The positive and negative predictive values were
$83.0 \%$ and $39.3 \%$ for TVS, and $95.1 \%$ and $83.3 \%$ for hysteroscopy, respectively. They concluded that hysteroscopy can be better used than TVS in evaluating those patients with AUB. Our study, in contrast found that TVS was a little more accurate than hysteroscopy for differentiating normal from abnormal endometrial cavity.

The limitation of the current study was the low number of patients with conditions other than uterine polyps or hyperplasia thus not allowing direct comparison of the two methods for myoma, placental residual material and cancer.

\section{CONCLUSION}

Transvaginal sonography has a moderate diagnostic accuracy in detecting endometrial hyperplasia and other intrauterine pathology. TVS is safe, acceptable and easily available in most secondary and tertiary care setting and is noninvasive.

Akhnowledgment: I would like to thank DR, Mohammed Hesham Ahmed head of the Department of Histopathology in $\mathrm{Al}$ Agouza Police Hospital, for his help in examining the Histopathological part of this work.

\section{REFERENCES}

1. Albers JR, Hull SK and Wesley RM. (2010): Abnormal Uterine Bleeding. American Family Physician, 69: 1915-1926.

2. Bazot M, Darai E, Rouger J, Detchev R, Cortez A and Uzan S. (2010): Limitations of transvaginal sonography for the diagnosis of adenomyosis, with histopathological correlation. Ultrasound in Obstetrics and Gynecology: The Official Journal of the International Society of Ultrasound in Obstetrics and Gynecology, 20(6): 605-611. 
3. Choudhary J, Acharya $\mathrm{V}$ and Jain $M$. (2017): Evaluation of abnormal uterine bleeding with transvaginal sonography and hysteroscopy in perimenopausal women. International Journal of Reproduction, Contraception, Obstetrics and Gynecology, 6(8): 3607-13.

4. Clark TJ. (2018): Hysteroscopy or Curettage? In: Hysteroscopy. Pbl. Springer, Cham., Pp. 141-148.

5. Dueholm $M$ and Hjorth IMD. (2017): Structured imaging technique in the gynecologic office for the diagnosis of abnormal uterine bleeding. Best Practice \& Research Clinical Obstetrics \& Gynaecology, 40: 23-43.

6. El-Khayat W, Ibraheem F, Ahmed AM, Ramadan AA, Khalifa SE and Ebrahim MF. (2017): Assessment of Perimenopausal Bleeding Using Three-Dimensional Hysterography, Hysteroscopy, and Histopathology. Journal of Obstetrics, Gynecology and Cancer Research, 2(2): 23-29.

7. Özdemir S, Çelik Ç, Gezginç K, Kıreşi D and Esen H. (2010): Evaluation of endometrial thickness with transvaginal ultrasonography and histopathology in premenopausal women with abnormal vaginal bleeding. Archives of Gynecology and Obstetrics, 282(4): 395-399.

8. Patil SG, Bhute SB, Inamdar SA, Acharya NS and Shrivastava DS. (2011): Role of diagnostic hysteroscopy in abnormal uterine bleeding and its histopathologic correlation. Journal of Gynecological Endoscopy and Surgery, 1(2): 98-102.

9. Pillai SS. (2014): Sonographic and histopathological correlation and evaluation of endometrium in perimenopausal women with abnormal uterine bleeding. International Journal of Reproduction, Contraception, Obstetrics and Gynecology, 3(1): 113-7.
10. Ratner RT, Tsaltas $\mathbf{J}$ and Vollenhoven B. (2019): Hysteroscopy and the risk of gas embolism: A review. Journal of Endometriosis and Pelvic Pain Disorders, 22: 140-147.

11. Ryu JA, Kim B, Lee J, Kim S and Lee SH. (2010): Comparison of transvaginal ultrasonography with hysterosonography as a screening method in patients with abnormal uterine bleeding. Korean Journal of Radiology, 5(1): 39-46.

12. Shobhitha GL, Kumari VI, Priya PL and Sundari BT. (2015): Endometrial study by TVS and It's correlation with histopathology in abnormal uterine bleeding. J Dental Med Sci., 14(4): 21-32.

13. Shokouhi B. (2015): Role of transvaginal ultrasonography in diagnosing endometrial hyperplasia in pre-and post-menopause women. Nigerian medical journal: journal of the Nigeria Medical Association, 56(5): 353-8.

14. Sun Y, Wang Y, Mao L, Wen J and Bai W. (2018): Prevalence of abnormal uterine bleeding according to new International Federation of Gynecology and Obstetrics classification in Chinese women of reproductive age: A cross-sectional study. Medicine, 97(31): 135-142.

15. Veena BT and Shivalingaiah N. (2014): Role of transvaginal sonography and diagnostic hysteroscopy in abnormal uterine bleeding. Journal of clinical and diagnostic research: JCDR, 8(12): 6-9.

16. Verma U, Garg R, Singh S, Yadav $P$ and Rani R. (2014): Diagnostic Approach in Perimenopausal Women with Abnormal Uterine Bleeding. Journal of Safoms, 2(1): 1216.

17. Whitaker L and Critchley HO. (2016): Abnormal uterine bleeding. Best Practice \& Research Clinical Obstetrics \& Gynaecology, 34: 54-65. 


\section{دراسة مقارتة دقة الموجات فوق الصوتية عن طريق المهبل والمنظار

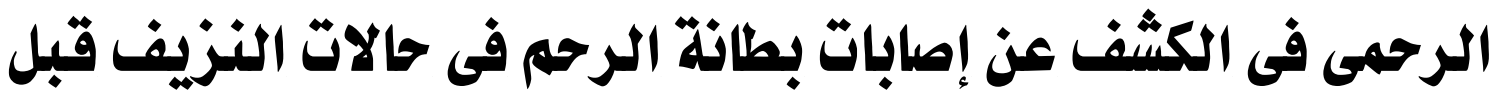 سن الهأس}

عمرو عبدالله رشدى حسن، اسماعيل محمد الجارحى، أشرف حمدى محمد قسم أمراض النساء والتوليد، كلية الطب، جامعة الأزهر

E-mail: amrroshdy321@gmail.com

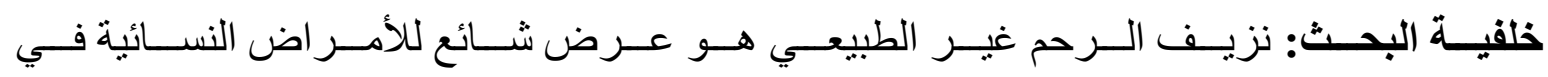

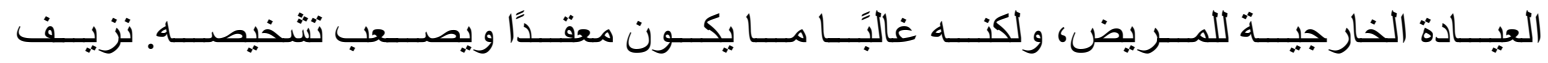

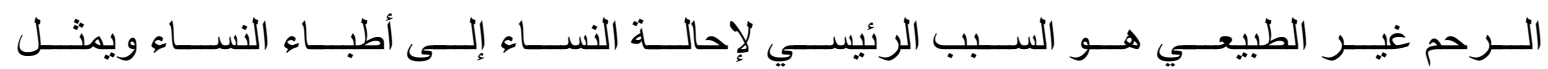

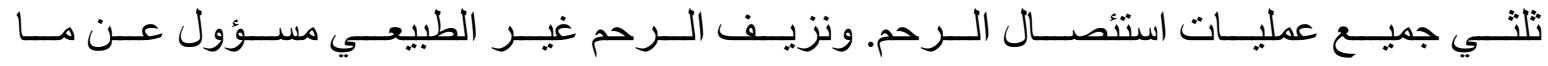

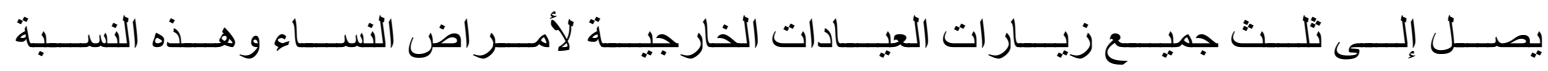
ترتفع إلى 69\% في مجمو عة ما حول انقطاع الطمث.

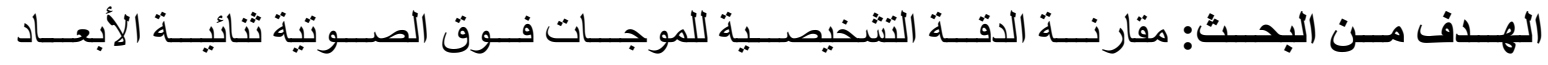

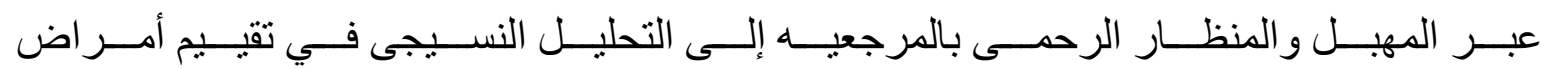

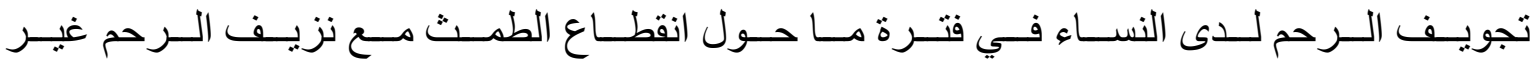
الطبيعي.

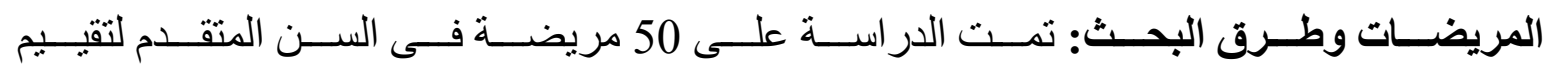

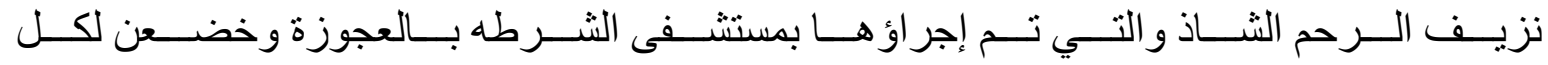

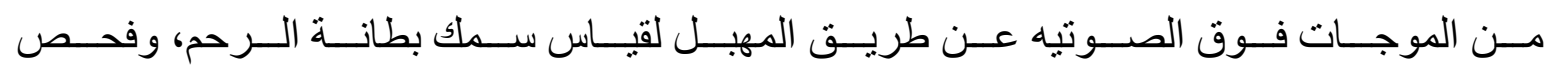

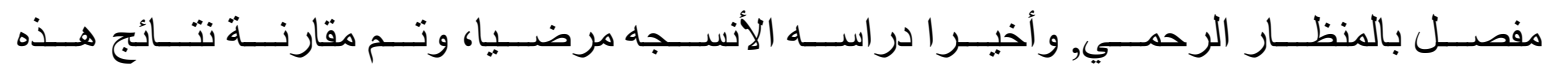

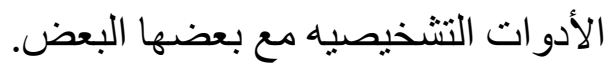

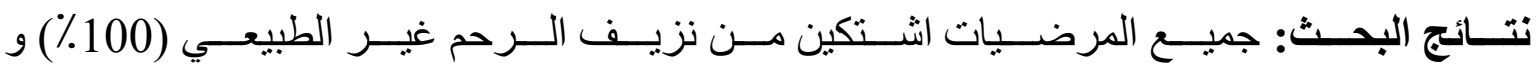

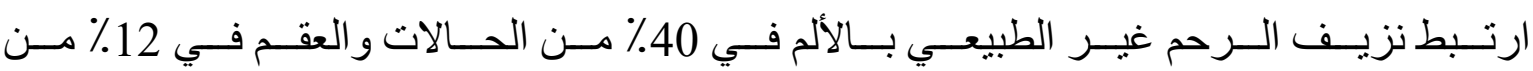

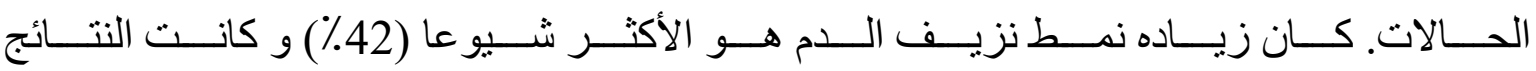

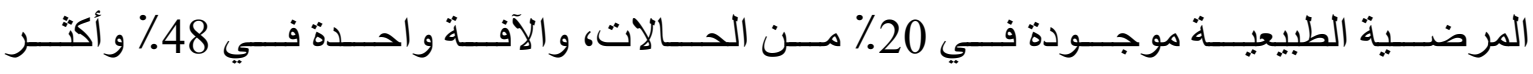

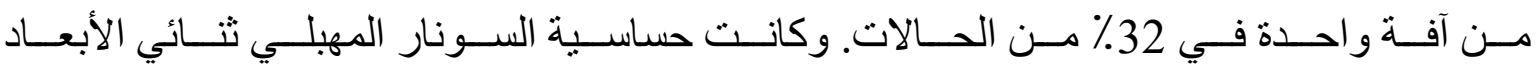




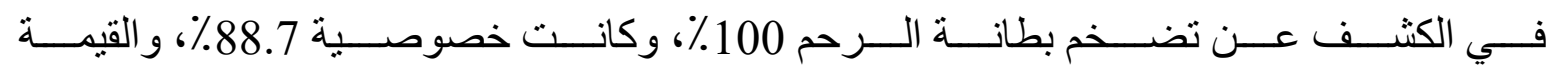

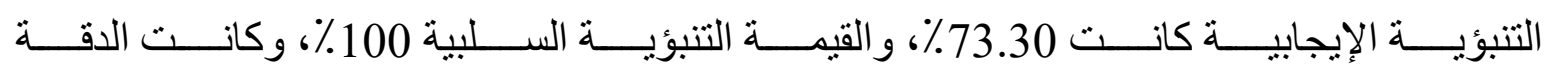

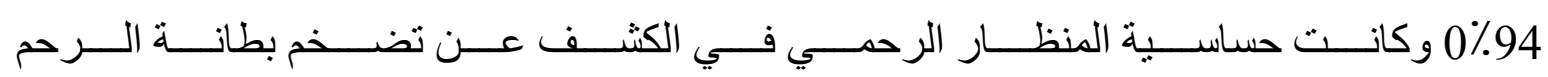

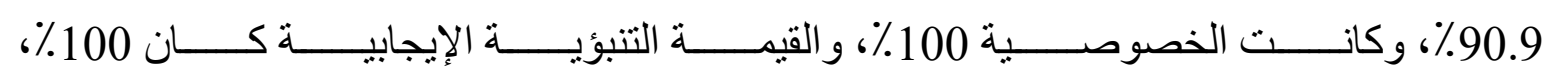

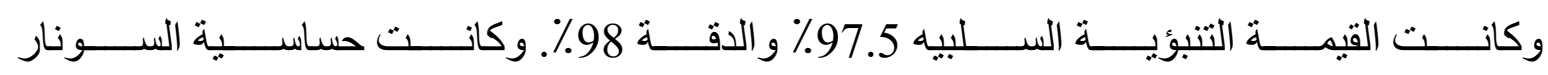

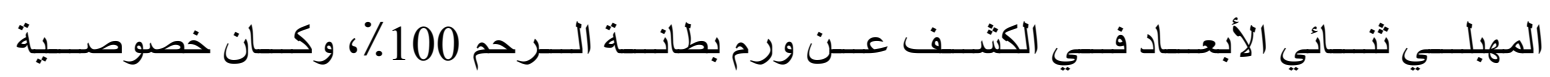

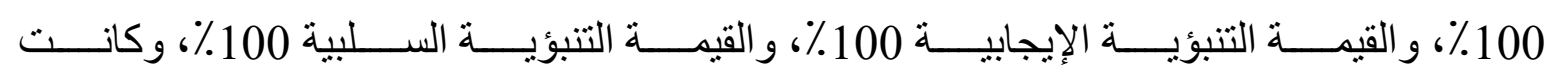

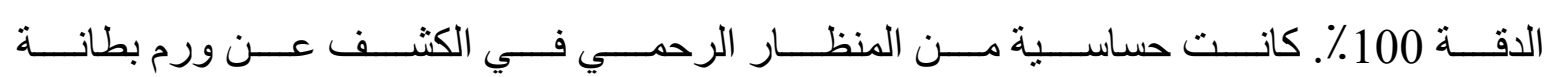

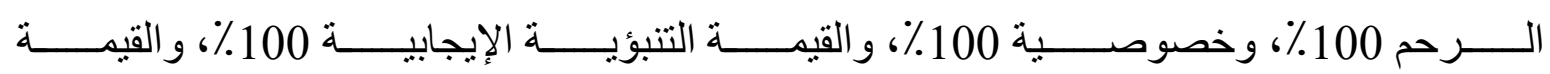
التنبؤية السلبية 100٪، و الدقة 100٪\% و 100٪

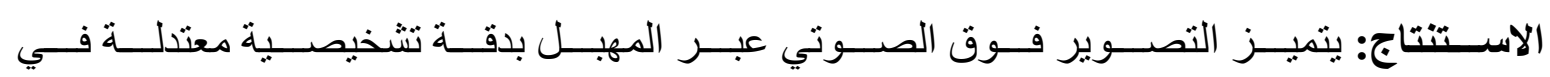

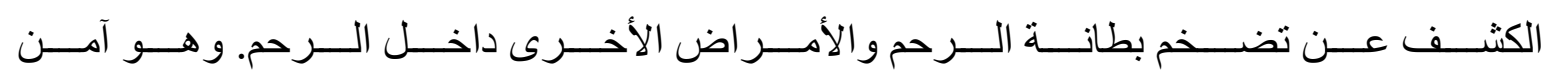

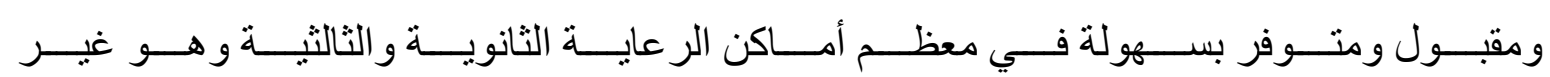

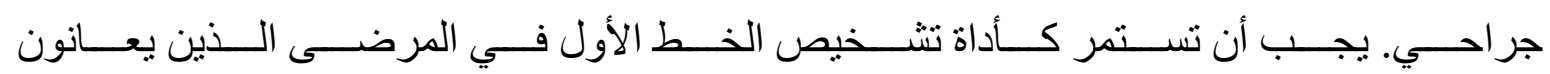
من نزيف الرحم غير الطبيعي عند النساء في فنرة ما قبل انقطاع الطمث.

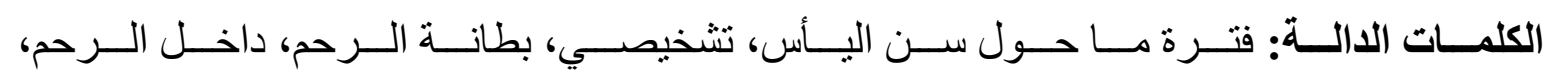
تنظير الرحم. 